\title{
Apgar values lower than 7 associated with mortality in premature newborns
}

\author{
A retrospective study
}

Nayeri Reyes-Saavedra, MD, Patricia C. Castelán-Villagrana, MD, Ivette Mata-Maqueda, MD, PhD, Juan C. Solís-Sáinz, MD, PhD.

\section{ABSTRACT}

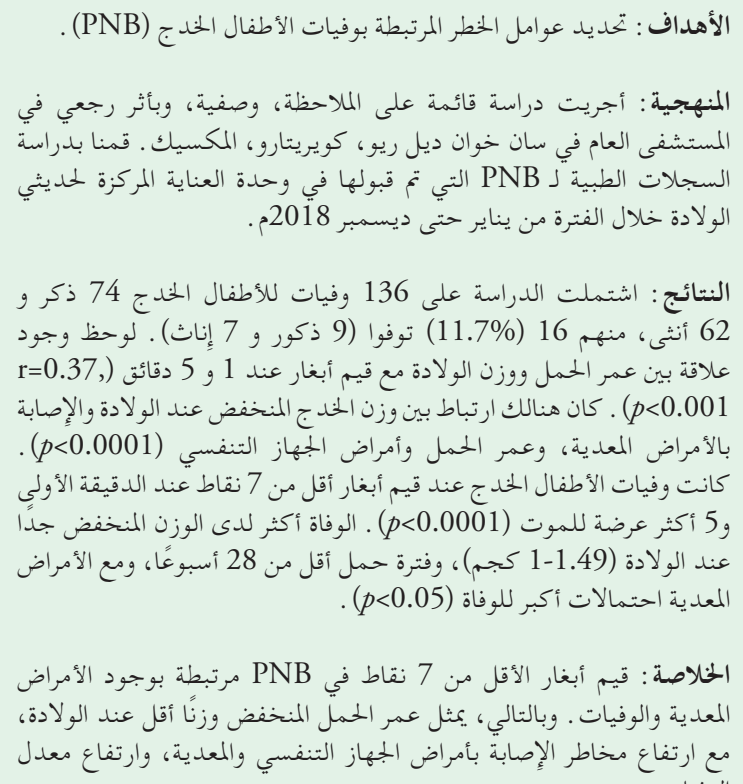

Objectives: To determine the risk factors associated with mortality in premature newborns (PNB).

Methods: An observational, descriptive, and retrospective study, carried out at the General Hospital of San Juan del Rio, Queretaro, Mexico. The medical records of PNB admitted to the Neonatal Intensive Care Unit from January until December 2018 were studied.

Results: A total of 136 PNB were included (74 males and 62 females) of whom 16 (11.7\%) died (9 males and 7 females). A correlation was observed between gestational age and birth weight with Apgar values at 1 and 5 minutes $(r=0.37, p<0.001)$. A lower birth weight was found in premature infants with infectious diseases, as well as a lower gestational age in relation to respiratory diseases $(p<0.0001)$. The PNB with Apgar values lower than 7 points at 1 and 5 minutes were more likely to die $(p<0.0001)$. The PNB with very low birth weight (1-1.49 kg), with less than 28 weeks of gestation, and with infectious pathology showed more probabilities of dying $(p<0.05)$.

Conclusion: Apgar values lower than 7 points in the PNB are associated with the presence of infectious diseases and mortality. Likewise, a lower gestational age represents a lower birth weight, with a higher risk for respiratory and infectious diseases, and consequently an elevated mortality.

Keywords: premature birth, Apgar score, gestational age, birth weight

Saudi Med J 2022; Vol. 43 (3): 252-258

doi: $10.15537 /$ smj.2022.43.3.20210641

From the Department of Internal Medicine (Reyes-Saavedra); from the Department of Psychiatry (Castelán-Villagrana), Health Services of the State of Hidalgo, Hidalgo, from the Department of Education (Mata-Maqueda), Health Services of the State of Queretaro, Queretaro, and from the Department of Biomedical Research (Solis-Sainz), School of Medicine, Autonomous University of Queretaro, Queretaro, Mexico.

Received 12th August 2021. Accepted 26th December 2021.

Address correspondence and reprint request to: Dr. Juan C. Solis-Sáinz, Professor, Department of Biomedical Research, School of Medicine, Autonomous University of Queretaro, Queretaro, Mexico.E-mail: carlos.solis@uaq.mx

ORCID ID: https://orcid.org/0000-0003-4558-1198

Drematurity is the leading cause of perinatal mortality in the world. The World Health Organization (WHO) defines a premature infant as "a live baby born before 37 weeks of gestation". Worldwide, it is estimated that each year approximately 15 million children are born prematurely, that is more than one premature in 10 births. The global prevalence of preterm births ranges between 5-18\% in developed and developing countries. ${ }^{1}$ Premature infants present on average 20 times more risk of dying than those born at term, and complications 
related to prematurity cause approximately one million deaths per year, of which up to $75 \%$ could be prevented with appropriate interventions. ${ }^{2}$ Each year in Latin America and the Caribbean, almost 12 million new births are registered, of which approximately 180,000 die in the first month of life. ${ }^{3}$ The incidence of premature births in Latin America is approximately 8.1\%, with a value of $7.7 \%$ in Mexico. ${ }^{4}$

Neonatal mortality is determined by multiple factors related to biological, healthcare system and socioeconomic variables. Among the most frequent causes of preterm birth are history of premature birth (it is found in $30 \%$ of the cases), maternal age of risk ( $<16$ years and $>35$ years), multiple pregnancy, a short intergenesic period, previous cesarean section, urinary tract infection, premature rupture of membranes, vaginal infection, periodontal infection, chronic-degenerative diseases, inadequate weight before pregnancy, substance abuse, low socioeconomic level, and low education. ${ }^{5,6}$

The main causes of neonatal mortality are asphyxia, respiratory distress syndrome and infections, followed by congenital malformations. ${ }^{7}$ Cerebral palsy, sensory deficits, learning disorders, and respiratory diseases occur more frequently in children born prematurely. These morbidities result in great long-term physical, psychological, and economic costs. ${ }^{8}$ The aim of this study was to determine the risk factors associated with mortality in premature newborns (PNB).

Methods. This is an observational, retrospective, and cross-sectional study, carried out at the General Hospital of San Juan del Río (GHSJR), Queretaro, Mexico, part of the Health Services of the State of Queretaro (SESEQ), Mexico. The medical records of all PNB admitted to the Neonatal Intensive Care Unit (NICU) of the GHSJR during the period from January until December of 2018 were studied. The database of the Pediatrics Department and the database repository (REDSSA, SESEQ) were employed. Among the total of PNB born at the GHSJR, 55\% of them required admission to the NICU, mainly due to respiratory disease (namely, respiratory distress syndrome, transient tachypnea, pulmonary adaptation syndrome, and apnea) and infectious disease (ID). Figure 1 shows the inclusion process of the 136 PNB medical records in this study. Exclusion criteria were incomplete or missing medical records and temporary admissions. The

Disclosure. Authors have no conflict of interests, and the work was not supported or funded by any drug company. variables analyzed were birth weight, gestational age, Apgar scores at 1 and 5 minutes, the diagnosis at the admission, the diagnosis at the discharge, delivery route of the pregnancy, the days number of hospital stay, mortality, maternal age, maternal history of personal pathological antecedents, and maternal education. In this study, the ethical precepts of the Declaration of Helsinki were followed, and it was approved in October, 2019 by the Research Committee of Health Services of the State of Querétaro, Mexico (registration no.: 1130/HGSJR/28/INTERNADO DE PREGRADO/ OCTUBRE2019/MIP).

Statistical analysis. Descriptive statistics were used in the qualitative variables, continuous and categorical variables are shown as means, standard deviations, frequencies, and percentages. Differences between categorical variables were evaluated by Fisher's exact tests and by analysis of variance (ANOVA) for continuous variables. A $p$-value of $<0.05$ was considered significant. The normality in the distribution of the variables was assessed by the Kolmogorov-Smirnov test for all the variables analyzed. Mann-Whitney and Kruskal-Wallis tests were used to evaluate the difference between

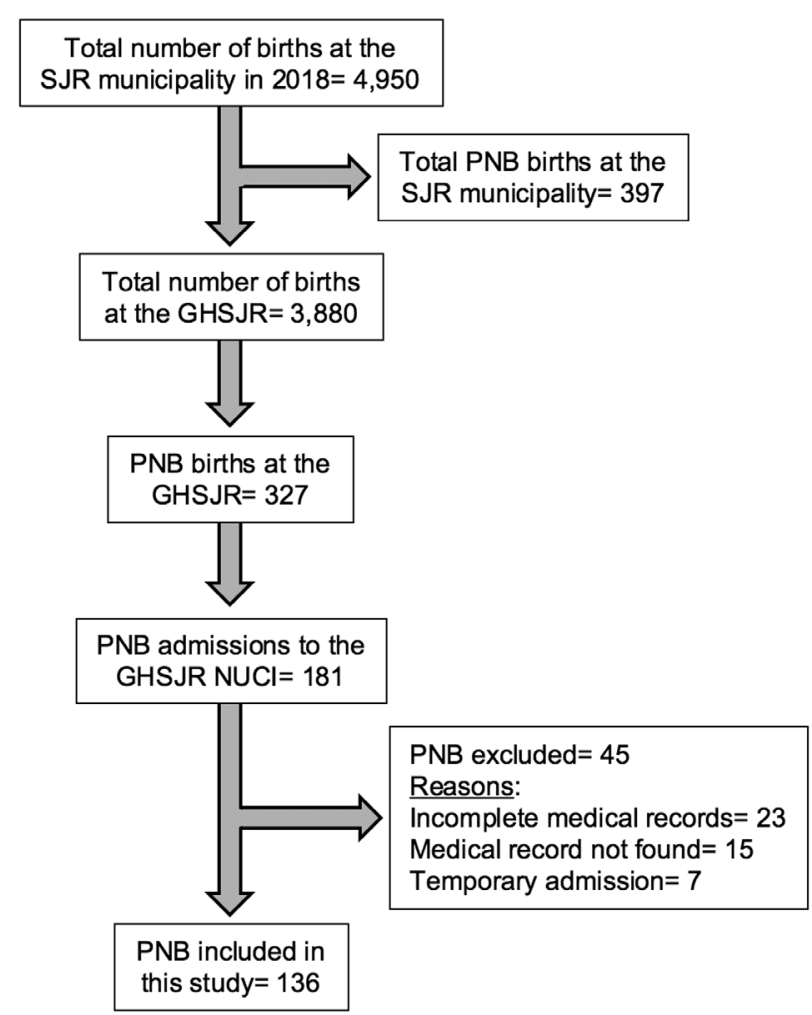

Figure 1 - Diagram of the premature newborns selection and inclusion process in the present study. SJR: San Juan del Río Hospital, PNB: premature newborns, GHSJR: General Hospital of San Juan del Río, NICU: neonatal intensive care unit. 
medians, as well as one-tailed Spearman correlations for all the unnormal distributed data. Binary logistic regression analyses were carried out to associate the variables studied with the PNB's death as a dependent variable. Gestational age, gender, and Apgar values at 1 and 5 minutes were used as covariates. Statistical Package for the Social Sciences for Windows, version 25 (IBM Corp., Armonk, NY, USA) was used for the analyses.

Results. As shown in Table 1, our sample included 74 (54\%) males and 62 (46\%) females. Most PNB were late preterms $(89 \%$, corresponding to 32-37 weeks of gestation), with low birth weight (64\%, corresponding to $1.5-2.49 \mathrm{~kg}$ ), and born by caesarean delivery $(72 \%)$.

When comparing maternal education with PNB birth weight, no differences were found $(p>0.05)$. In relation to maternal education and mothers age, no significant differences were found either.

However, when comparing gestational age in relation to maternal education, it was observed that mothers with a bachelor's degree had a lower gestational age (median values of 33.6), compared to mothers with elementary and middle school (median values of 35.3; $p=0.02$ ).

The presence of a gynecological and obstetric risk factor (namely, previous abortion, history of preterm delivery, threatened miscarriage, and threatened preterm labor) did not relate to lower gestational age $(p=0.49)$. Similarly, the history of drug addiction $(p=0.4)$ and chronic degenerative diseases (CDD, $p=0.09$ ) in the current pregnancy were not related to a lower gestational age. Maternal age over 35 years old was not associated with a lower gestational age $(p=0.139)$. Furthermore, when a correlation was carried out between gestational age and maternal age, no statistical difference was found $(p=0.1)$.

In relation to maternal age and the presence of $\mathrm{CDD}$, it was found that mothers with this type of pathological antecedent were older (median values of 26 versus 30 years of age; $p=0.04$ ). Likewise, PNB whose mothers had a history of CDD showed a higher birth weight (median values of 2.12 versus $2.43 \mathrm{~kg}$; $p=0.0006$ ).

No differences were found at birth weight by gender $(p=0.23)$. Nor were differences found in the days number of hospital stay in relation to gender $(p=0.11)$. However, when analyzing the PNB birth weight in the deceased group, differences were found in relation to gender. Deceased males (mean value of $1.47 \mathrm{~kg}$ ) showed a higher birth weight than deceased females (mean value of $1.04 \mathrm{~kg} ; p=0.04$ ). No differences were found between gestational age in relation to gender in
Table 1 - General characteristics of the population.

\begin{tabular}{lc}
\hline Variable & $\mathbf{n}(\%)$ \\
\hline Gender & \\
Male & $74(54.0)$ \\
Female & $62(46.0)$ \\
Gestational age & \\
Late preterm (32-37 WG) & $121(89.0)$ \\
Early preterm (28-31.6 WG) & $10(7.4)$ \\
Extremely premature (<28 WG) & $5(3.6)$ \\
Birth weight & \\
Suitable (>2.5 kg) & $32(23.5)$ \\
Low (1.5-2.49 kg) & $87(64.0)$ \\
Very low (1-1.49 kg) & $11(8.0)$ \\
Extremely low (<1 kg) & $6(4.5)$ \\
Apgar value (median \pm IR) & \\
At 1 minute & $8 \pm 0.1$ \\
At minute 5 & $9 \pm 0.1$ \\
Route of delivery & \\
Vaginal birth & $38(28.0)$ \\
Caesarean section & $98(72.0)$ \\
Maternal education & \\
Primary school & $34(25.0)$ \\
Middle school & $73(53.6)$ \\
High school & $19(14.0)$ \\
Bachelor's degree & $10(7.4)$ \\
Maternal age (median $\pm \mathrm{IR})$ & $26.5 \pm 3$ \\
Days of hospital stay (median $\pm \mathrm{IR})$ & $10 \pm 2$ \\
Mothers with a history of CDD & $13(8.0)$ \\
Mothers with OGRF & $115(84.5)$ \\
PNB with respiratory diseases & $74(54.4)$ \\
PNB with infectious diseases & \\
\hline & \\
& \\
&
\end{tabular}

WG: weeks of gestation, IR: interquartile range, CDD: chronic degenerative disease, OGRF: obstetrics and gynecological risk factors (namely, previous abortion, history of preterm delivery, threatened miscarriage, and threatened preterm labor), PNB: premature newborn

the PNB $(p=0.22)$. A lower birth weight was observed among the deceased PNB (average value of $1.28 \mathrm{~kg}$ ) versus the alive PNB (average value of $2.22 \mathrm{~kg} ; p<0.001$.

No significant correlation was found between maternal age and Apgar values both at 1 minute $(p=0.09)$ and 5 minutes $(p=0.15)$. There was also no difference between the route of delivery (namely, vaginal birth or cesarean section) and the Apgar values at 1 minute $(p=0.14)$ and 5 minutes $(p=0.34)$. In the case of the deceased PNB, a lower Apgar value was found at 1 minute (median values of 8 versus $6 ; p=0.0001$ ) and at 5 minutes (median values of 9 versus 8 ; $p=0.0001$ ). When analyzing the Apgar value in relation to gestational age, a significant positive correlation was found with both the 1 and 5 minutes Apgar values (Figure 2). 
In relation to the Apgar values (both at 1 and 5 minutes) and birth weight, a positive correlation was found between both variables (Figure 3).

Likewise, the Apgar value at minute 5 was lower in the PNB with the presence of ID (median values of 8.7 versus $8.4 ; p=0.01$ ). However, the premature infant with respiratory diseases did not show differences in the Apgar values at 1 minute $(p=0.09)$ or at 5 minutes $(p=0.26)$.

Morbidity of PNB. A lower gestational age was found in PNB infants with a diagnosis of ID (median values of 34.2 versus 35.5 weeks of gestation [WG]; $p<0.0001$ ) and respiratory diseases (median values of 35 versus $36 \mathrm{WG} ; p=0.007$ ) versus $\mathrm{PNB}$ infants who did not have these diseases. In the case of prematures diagnosed with ID, a lower birth weight was also found (Figure 4) but not so with premature infants with the presence of respiratory diseases $(p=0.16)$.

Mortality of PNB. No differences were found in terms of gender, route of delivery, maternal education
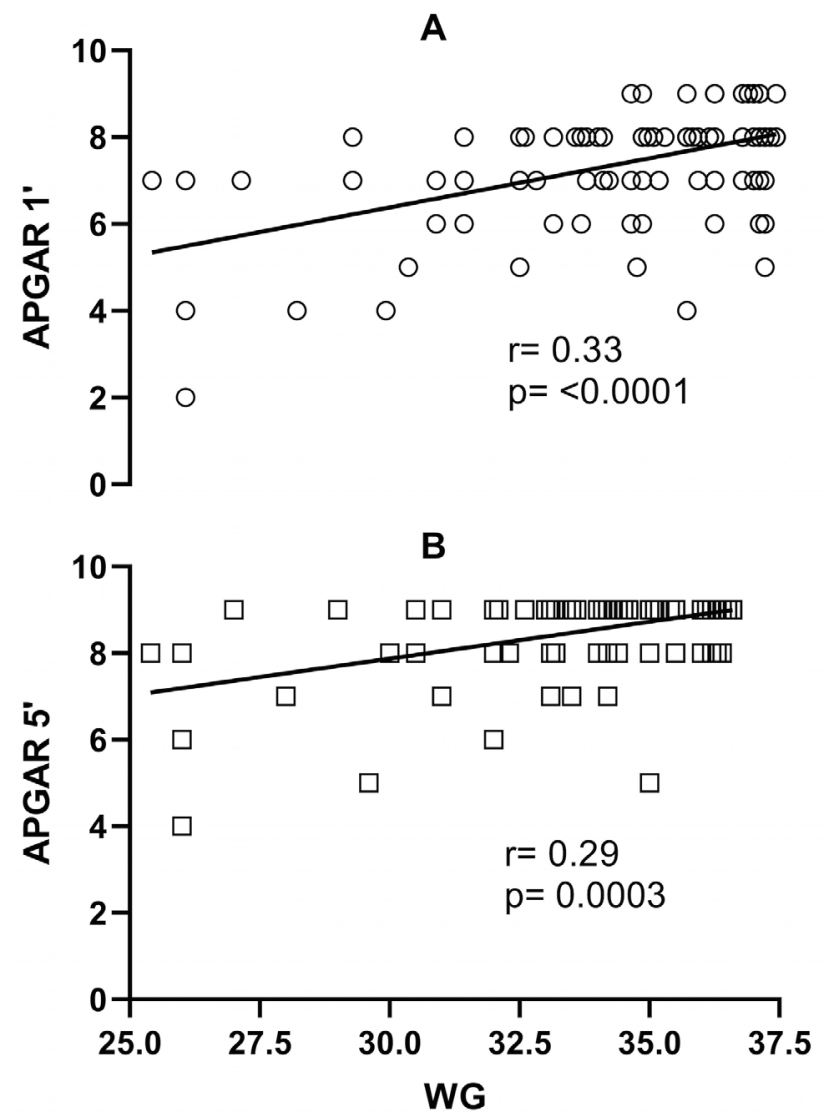

Figure 2 - Correlation between: A) the 1 minute and B) 5 minutes Apgar values versus the premature newborns gestational age. A Spearman correlation was carried out for the 136 reported Apgar values. WG: weeks of gestation lower than 6 years, maternal age older than 35 years, more than 10 days of hospital stay, and the presence of respiratory diseases, in relation to the PNB mortality (Table 2).

Table 2 shows the associations found between different variables with the PNB mortality. An association was found between death and the variables of gestational age of less than 32 and 28 WG, Apgar value lower than 7 points at 1 and 5 minutes, presence of infectious pathology, a birth weight lower than $2.1 \mathrm{~kg}$, as well as very low birth weight $(1-1.49 \mathrm{~kg})$, and extremely low birth weight (less than $1 \mathrm{~kg}$ ).

Discussion. Advanced maternal age has traditionally been described as a risk factor for prematurity. Approximately $90 \%$ of premature births were reported in a literature in the group of mothers older than 40 years of age. ${ }^{9}$ However, in the present study we did not find differences in relation to maternal age, where
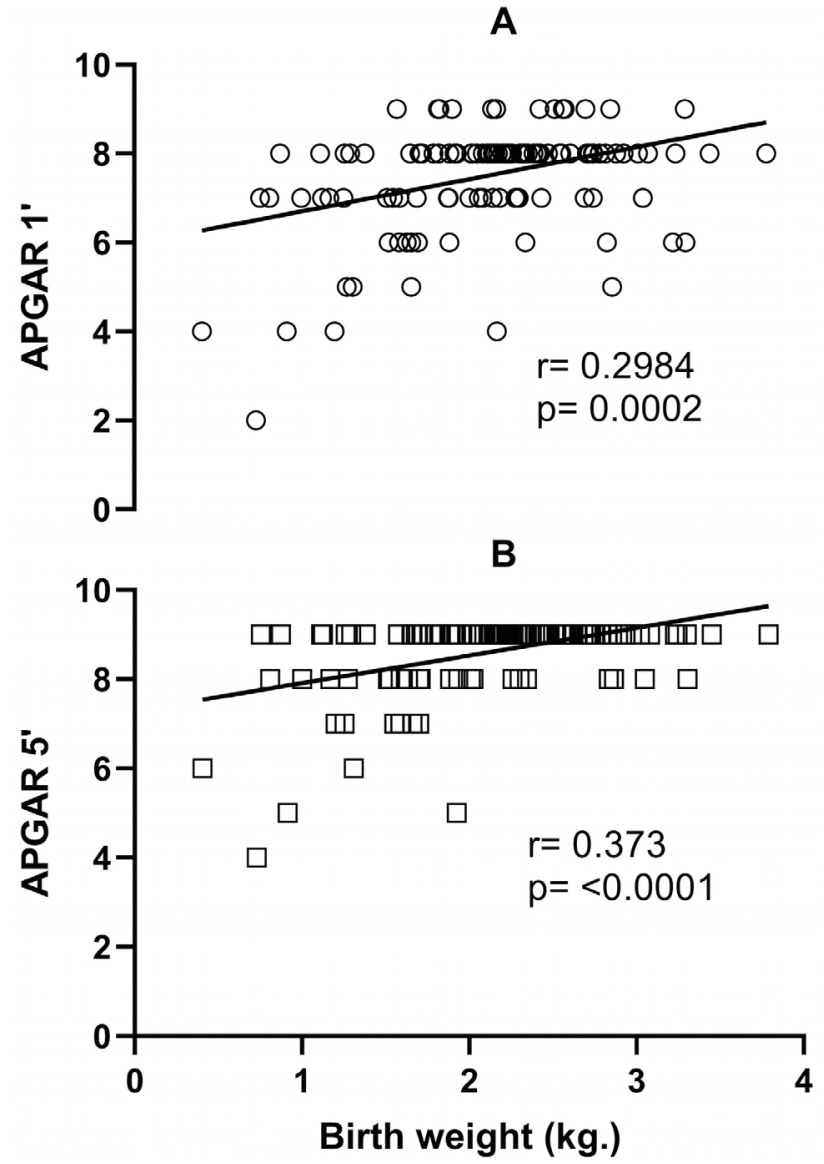

Figure 3 - Correlation between Apgar values at A) 1 minute and B) 5 minutes versus premature newborns birth weight. A Spearman correlation was carried out for the 136 reported Apgar values. kg: kilogram 


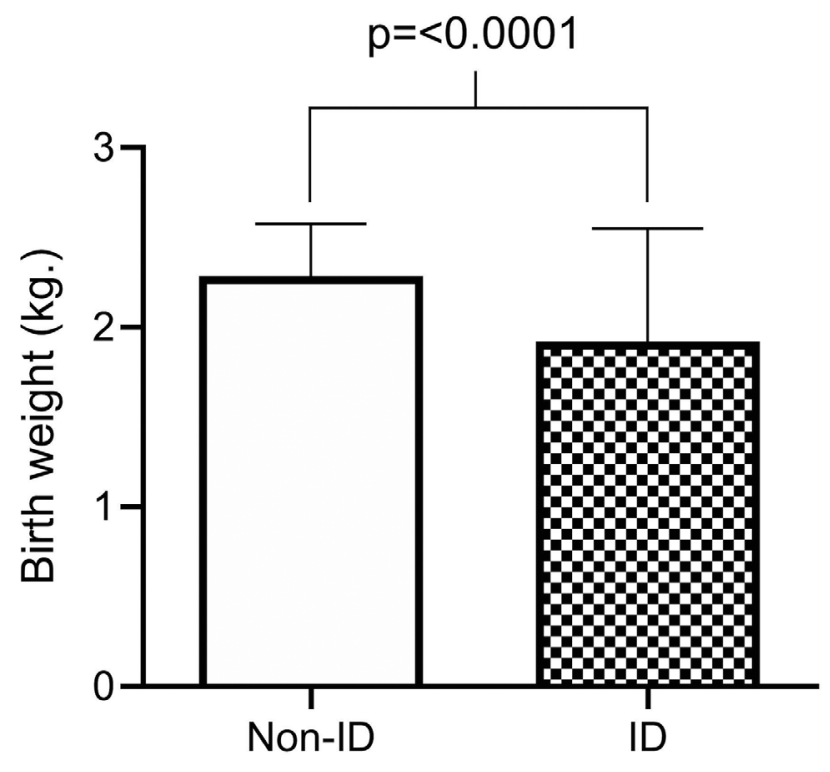

Figure 4 - Comparison of birth weight in premature newborns (PNB) without and with the presence of ID. A Mann-Whitney test was carried out, 62 PNB without the diagnosis of infection (median value of $2.28 \mathrm{~kg}$ ) and 74 with a diagnosis of infections (median value of $1.88 \mathrm{~kg}$ ) were analyzed. Median values \pm interquartile ranges are shown. ID: infectious diseases

we observed a median of less than 30 years of age. Likewise, another factor associated with prematurity is a low maternal education. Nevertheless, in this study, the PNB of mothers with bachelor's degree education showed a lower gestational age. This could probably be related to their professional or work activity, which might increase the risk of prematurity. ${ }^{10}$

Another risk factor associated with prematurity is the antecedent of CDD, such as type 2 diabetes, hypertension, obstetric and gynecological risk factors, including placenta previa, history of preterm delivery, preeclampsia, gestational diabetes, twin pregnancy, oligohydramnios, premature rupture of membranes, and cervicovaginitis. ${ }^{1,10,11}$ However, in this study we did not find an association between this type of risk factors and a lower gestational age.

Regarding gender and prematurity, a higher prevalence in males compared to females has traditionally been described. Several mechanisms have been proposed to explain this difference, as a higher weight to lower gestational ages and an increased susceptibility to complications associated with males that could generate premature labor. ${ }^{12,13}$ However, in the present study we did not find differences in birth weight and gestational age in relation to gender. Likewise, males have also been associated with a higher risk of mortality in prematurity. ${ }^{1,13}$ In consistent with this observation, in this study the deceased premature males showed a significantly greater weight, compared to the deceased females. However, we did not find differences in the deceased PNB in relation to gender.

In relation to the Apgar value, it was generally recognized that low values were directly proportional to gestational age, which was considered a reflection of the biological immaturity of PNB. ${ }^{14}$ In the present study the gestational age and birth weight positively correlated with the 1 and 5 minutes Apgar values. In this regard, we considered that the Apgar value provided substantial information about the prognosis of the PNB's health status, thus reflecting its biological maturity status.

The association between a low Apgar score at 5 minutes with the presence of neonatal sepsis has been already reported in other literatures. ${ }^{15,16}$ In the present study, we found lower average Apgar values at minute 5 in PNB with ID. A low Apgar value may also reflect perinatal asphyxia, favoring an alteration in the immune system response, therefore predisposing to the presence of ID.

It has also been reported that PNB had a higher prevalence of respiratory diseases. ${ }^{17}$ This was in accordance with what was found in this study, where it was observed that PNB with a lower gestational age showed respiratory pathology at birth. In relation to birth weight, it has also been described that newborns with lower birth weight were at increased risk of presenting ID. ${ }^{18}$ This idea was consistent with what was found in the present study, where the lower-weight PNB showed a higher presence of ID. This may be due to the immaturity of the defense mechanisms in the PNB, which in turn could increase the incidence of respiratory diseases. ${ }^{19}$

In relation to mortality in the $\mathrm{PNB}$, it has been previously described that an Apgar score lower than 7 points at 5 minutes represented low vitality and was associated with perinatal death. ${ }^{20}$ Indeed, in the present study it was found that the PNB with an Apgar value lower than 7 points both at 1 and 5 minutes were 16 and 25 times more likely to die.

The association between the presence of infectious pathology and the death of PNB has also been described in a previous literature. ${ }^{21}$ In the present study, it was found that PNB with a diagnosis of infectious pathology were 62 times more likely to die.

A low birth weight has been previously associated with mortality in PNB. ${ }^{22}$ This was consistent with the findings in the present study, where PNB with a lower than the average birth weight in our study sample were 8.5 times more likely to die, while premature infants with a very low birth weight (1-1.49 kg) and extremely 
Table 2 - Association of risk factors with mortality in the PNB.

\begin{tabular}{|c|c|c|c|}
\hline \multirow[t]{2}{*}{ Variables } & \multicolumn{3}{|c|}{ Deaths $(n=16)$} \\
\hline & n (\%) & OR $(95 \% \mathrm{CI})$ & $P$-value \\
\hline Male gender & $9(56.2)$ & $1.08(0.3-3.1)$ & 0.54 \\
\hline Route of delivery by caesarean section & $12(75)$ & $1.1(0.3-3.5)$ & 0.52 \\
\hline Maternal education ( $<6$ years) & $3(18.7)$ & $0.6(0.2-2.3)$ & 0.41 \\
\hline Maternal age ( $>35$ years) & $17(12.5)$ & $2(0.2-10)$ & 0.31 \\
\hline Days of hospital stay $(>10)$ & $10(62.5)$ & $2.1(0.4-10.1)$ & 0.312 \\
\hline Presence of respiratory diseases & $15(93.7)$ & $1.8(0.2-14.8)$ & 0.291 \\
\hline Gestational age (<32 WG) & $9(56.2)$ & $24.4^{\dagger}(6.7-88.3)$ & $<0.0001^{*}$ \\
\hline Gestational age (<28 WG) & $5(31.2)$ & $54^{\dagger}(5.8-505)$ & $<0.0001^{*}$ \\
\hline Apgar value at one minute $(<7)^{\ddagger}$ & $13(81.2)$ & $16.2^{\dagger}(3.4-76)$ & $<0.0001^{*}$ \\
\hline Apgar value at 5 minutes $(<7)^{\ddagger}$ & $7(43.7)$ & $25.1^{\dagger}(6-104)$ & $<0.0001^{*}$ \\
\hline Presence of infectious diseases & $15(93.7)$ & $61.9^{\dagger}(1.1-361)$ & $0.047^{*}$ \\
\hline Birth weight $(<2.1 \mathrm{~kg})^{\S}$ & $14(87.5)$ & $8.5^{\dagger}(1.5-49)$ & $0.016^{*}$ \\
\hline Very low birth weight (1-1.49 kg) & $6(37.5)$ & $27.3^{\dagger}(6.8-121)$ & $0.001^{*}$ \\
\hline Extremely low weight at birth $(<1 \mathrm{~kg})$ & $5(31.2)$ & $47^{\dagger}(2.4-901)$ & $0.011^{*}$ \\
\hline
\end{tabular}

${ }^{\dagger}$ These OR values were corrected for gender, WG, apgar values at 1 and 5 minutes, and days of hospital stay, using binary logistic regression analyses, ${ }^{\ddagger}$ the 7 points cut-off point for the apgar value corresponds to 25 th percentile, both for the 1 and 5 minutes values, ${ }^{5}$ the $2.1 \mathrm{~kg}$ cut-off point for birth weight corresponds to the 50th percentile of this variable, "significant $p$-values $(p<0.05)$, PNB: premature newborn, OR: odd ratio, CI: confidence interval, WG: weeks of gestation, kg: kilogram

low birth weight $(<1 \mathrm{~kg})$ showed a risk of death 27 and 47 times higher.

As for the gestational age and its impact on mortality, it was known that there was an association between lower gestational age and mortality in PNB. ${ }^{23}$ This was consistent with what was found in this study, where a gestational age lower than $32 \mathrm{WG}$ associated with a 24-fold increased the probability of dying, while a gestational age lower than $28 \mathrm{WG}$ in PNB associated with a 54-fold increased the probability of dying.

Contrary to what has been described by various studies, in this study we found no association between mortality of PNB with the variables of male gender, route of delivery by caesarean section, mother's schooling under 6 years, maternal age over 35 years, days of hospital stay, and the presence of respiratory disease. ${ }^{9,21,23,24}$

Study limitations. A relatively low sample, the lack of information regarding biochemical data associated with the diagnostic of perinatal asphyxia, the absence of body mass index, maternal values in order to classify the risk of preterm delivery, as well as the lack of data regarding maternal pathological antecedents such as the number of previous abortions, WG of the previous pregnancy, and the characteristics of the prenatal control.

In conclusion, the present study shows that Apgar values lower than 7 points in PNB are associated with the presence of ID and significantly increased mortality. In addition, a lower gestational age relates to a lower birth weight, a higher risk for respiratory and ID, and consequently, a higher risk of death. Furthermore, the application of adequate and timely neonatal resuscitation in the premature is of great relevance for the patient and the adequate prognosis of PNB.

Acknowledgment. The authors gratefully acknowledge Dr. Sergio E. Ramirez-Escutia, Dr. Gustavo A. Cuello-Ugalde, Dr. Alba Uribe-Miranda, and Dr. Maria del C. Martínez-Cervantes for their assistance and support in providing access to the medical records. We also thank Melina González-Ugalde and Guadalupe Ugalde-Alegria for their support in performing this study. We also would like to thank the Faculty of Languages and Letters of the Autonomous University of Querétaro, Mexico, for the English language editing.

\section{References}

1. Shim SY, Cho SJ, Kong KA, Park EA. Gestational age-specific sex difference in mortality and morbidities of preterm infants: a nationwide study. Sci Rep 2017; 7: 6161.

2. World Health Organization. Preterm birth. [Updated 2018; accessed 2021 June 10]. Available from: https://www.who.int/ news-room/fact-sheets/detail/preterm-birth

3. Observatorio de la Infancia en Addalucia. [Maternal and neonatal mortality in LAC and reduction strategies: summary of the situation and strategic approach]. [Updated 2008; accessed 2021 June 10; in Spanish] Available from: https:// www.observatoriodelainfancia.es/oia/esp/documentos_ficha. aspx?id=2183

4. Lopez-Garcia B, Avalos N, Diaz NB. [Incidence of premature newborns in the Naval General Hospital of High Specialty 2015-2017]. Rev Sanid Milit Mex 2018; 72: 19-23. [in Spanish] 
5. National Institute of Pediatrics. [Prematurity: challenges, prevention and management]. [Updated 2018; accessed 2021 June 10; in Spanish] Available at: https://www.pediatria.gob. $\mathrm{mx} /$ archivos/fasciculo_prematurez.pdf

6. Macías-Villa H, Moguel-Hernández A, Iglesias-Leboreiro J, Bernárdez-Zapata I, Braverman-Bronstein A. [Advanced maternal age as a perinatal and newborn risk factor]. Acta Médica Grupo Ángeles 2018; 16: 125-132. [in Spanish]

7. Carrera S, Hernández M, Fernández LA, González E, Corral E, Barrera PI, et al. [Neonatal mortality in a tertiary level care centre]. Perinatol Reprod Hum 2016; 30: 97-102. [in Spanish]

8. Dahman HAB. Risk factors associated with preterm birth: a retrospective study in Mukalla Maternity and Childhood Hospital, Hadhramout Coast/Yemen. Sudan J Paediatr 2020; 20: 99-110.

9. Escobar-Padilla B, Gordillo-Lara LD, Martínez-Puon H. [Risk factors associated with preterm birth in a second level hospital]. Rev Med Inst Mex Seguro Soc 2017; 55: 424-428. [in Spanish]

10. Rodríguez A, Hernández E, Villafuerte J, Mesa ZT, Hernández Y, López AM. [Risk factors associated with preterm birth]. Medisur 2019; 17: 505-513. [in Spanish]

11. Claros DI, Mendoza LA. [Impact of hypertensive disorders, diabetes, and maternal obesity on weight, gestational age at birth, and neonatal mortality. Rev Chil Obstet Ginecol 2016; 8: 480-488. [in Spanish]

12. Nascimento LFC, Blanco Machin A, Antonio Almeida Dos Santos D. Are there differences in birth weight according to sex and associations with maternal exposure to air pollutants? A cohort study. Sao Paulo Med J 2017; 135: 347-354.

13. Cnattingius S, Johansson S, Razaz N. Apgar score and risk of neonatal death among preterm infants. N Engl J Med 2020; 383: $49-57$.

14. Shim SY, Cho SJ, Kong KA, Park EA. Gestational age-specific sex difference in mortality and morbidities of preterm infants: a nationwide study. Sci Rep 2017; 7: 6161.

15. Rafi MA, Miah MMZ, Wadood MA, Hossain MG. Risk factors and etiology of neonatal sepsis after hospital delivery: a casecontrol study in a tertiary care hospital of Rajshahi, Bangladesh. PLoS One 2020; 15: e0242275.
16. Gebremedhin D, Berhe H, Gebrekirstos K. Risk factors for neonatal sepsis in public hospitals of Mekelle city, North Ethiopia, 2015: unmatched case control study. PLoS One 2016; 11: e0154798.

17. Condò V, Cipriani S, Colnaghi M, Bellù R, Zanini R, Bulfoni $\mathrm{C}$, et al. Neonatal respiratory distress syndrome: are risk factors the same in preterm and term infants? J Matern Fetal Neonatal Med 2017; 30: 1267-1272.

18. Alfonso K, Rodríguez E, Duthil S. [Clinical and epidemiological aspects in patients with neonatal infection]. MEDISAN 2016; 20: 1037-1046. [in Spanish]

19. Collins A, Weitkamp JH, Wynn JL. Why are preterm newborns at increased risk of infection? Arch Dis Child Fetal Neonatal Ed 2018; 103: F391-F394.

20. Moura BLA, Alencar GP, Silva ZPD, Almeida MF. Factors associated with hospitalization and neonatal mortality in a cohort of newborns from the Unified Health System in São Paulo. Rev Bras Epidemiol 2020; 23: e200088.

21. Manríquez PG, Escudero OC. [Analysis of risk factors for neonatal death in Chile, 2010-2014]. Rev Chil Pediatr 2017; 88: 458-464. [in Spanish].

22. Victora JD, Silveira MF, Tonial CT, Victora CG, Barros FC, Horta BL, et al. Prevalence, mortality and risk factors associated with very low birth weight preterm infants: an analysis of 33 years. J Pediatr (Rio J) 2020; 96: 327-332.

23. Lona Reyes JC, Pérez Ramírez RO, Llamas Ramos L, Gómez Ruiz LM, Benítez Vázquez EA, Rodríguez Patino V. Neonatal mortality and associated factors in newborn infants admitted to a neonatal care unit. Arch Argent Pediatr 2018; 116: 42-48.

24. Marrugo-Arnedo CA, Arrieta-Arrieta A, Herrera-Malambo D, Díaz-Vargas LC, Pérez-Yepes C, Dueñas-Castell C. [Determinants of prolonged stay of neonates in intensive care unit]. Rev Cienc Salud (Bogotá Colombia) 2018; 17: 259-275. [in Spanish] 